\title{
ON THE COMBUSTION TEMPERATURE OF CIGARS AND CIGARETTES.
}

\author{
By Masuzo Shikata.
}

(Received Apr. 11th., 1926)

It is rather noticeable, that, although so many analysis have been carried out as to the chemical composition of smoke of cigar, no attempt seems to have been undertaken for a measurement of actual combustion temperature of cigars and cigarettes.

The present author has measured the temperature of combustion with a small enamelled iron-constantan thermocouple with its diameter of $0.14 \mathrm{~mm}$.

This thermocouple, when inserted directly in the axial center of cigars and cigarettes can give actual temperature of such small body as cigarette, owing to its very small heat capacity. The calibration of this thermocouple has been done with melting points of metallic tin, zinc and antimony.

The supply of air, of course, is one of the most important factors of combustion, that is to say, smoking, or better to say, sucking of cigarettes is one of the decisive factors for the combustion temperature.

Special cares having been payed in this respect, the measurements have been carried out.

The following table shows the stable maximum temperatures, i. e. maxima of stable temperature without sucking or with very slow sucking.

Table

$\begin{array}{ccccccc}\begin{array}{c}\text { Numbers of } \\ \text { experiments }\end{array} & \text { Asahi } & \text { Shikishima } & \text { Golden Bat } & \text { Star } & \text { Westminster } & \text { Cigar } \\ \mathbf{1} & 515 & 733 & 649 & 587 & 649 & 597 \\ 2 & 473 & 671 & 583 & 420 & 753 & 469 \\ 3 & 552 & 609 & 557 & 649 & 743 & 671 \\ 4 & 463 & 597 & 597 & 701 & 738 & 629 \\ 5 & 582 & 582 & 672 & 567 & 701 & 687 \\ 6 & 530 & 577 & 493 & 592 & 733 & \\ 7 & 619 & 520 & 649 & 671 & 749 & \\ 8 & 597 & 567 & 602 & 619 & 748 & \\ 9 & 711 & 557 & 530 & 723 & 671 & \\ 10 & 614 & 676 & 733 & 691 & \mathbf{7 9 5} & \\ \text { Mean } & 555.8 & 608.9 & 606.4 & 622 & 726.5 & 646.6\end{array}$

In the table, the first line is the names of cigars and cigarettes.

Asahi, Shikishima, Golden Bat and Star are Japanese cigarettes prepared by the Japanese Tobacco Monopoly Bureau. The cigar is "Orientales", also from the Monopoly Bureau. Westminster is Turkish Blend A. A. Grade, 
prepared by Westminster Tobacco Co. Ltd. London.

In Fig. 1. (in the original paper) the method of measurement has been graphically shown. In Fig. 2. the temperature change with time is manifested. Temperature is given by ordinate, time by abscissa in minutes. In this diagram process of combustion are clearly seen.

In case of the cigar the temperature increases gradually.

Such condition must be favourable for the distillation of nicotin, nicotein and other essential components.

In case of cigarettes the maximum temperature is attained suddenly, so that heat decomposition must set in, before most parts of essential components can be distilled or sublimated. It can be noticed that cigarettes of Westminster Tobacco Co. shows much higher combustion temperature than ordinary cigar, and latter has again higher combustion temperature than the Japanese cigarettes.

\title{
ON THE PRESENCE OF CYSTEINE GROUP IN PROTEIN MOLECULES.
}

\author{
By Yuzuru Okuda.
}

(Received May 29th., 1926)

The purpose of this investigation was to make some quantitative studies concerning the presence of cysteine group in the protein molecule, a subject on which, as far as we know, no work has hitherto been done.

I. Is Cysteine Produced Secondarily from Cystine during Prolonged Hydrolysis of Proteins?

Mörner ${ }^{(3)}$ has hydrolyzed some horn substance with hydrochloric acid for a week, and after removing the most part of the acid by evaporation, neutralized the hydrolysate with lead oxide, treated with hydrogen sulphide, and then filtered the precipitate, and after perfectly removing the excess of hydrogen sulphide tested cysteine in the filtrate by means of the nitroprusside reaction. And he has stated that cysteine is produced secondarily from cystine during prolonged hydrolysis of the protein. But we have failed to confirm his conclusion. We have repeated his procedure with pure cystine and with some keratine-cleavage-products free from cysteine, and have verified the facts that by Mörner's process cysteine should be produced from cystine by the reducing 